\title{
Effects of corn stem as a soil conditioner toward a green approach on waste management
}

\begin{abstract}
This study examined the period of time that is needed for corn stem to degrade into soil in order to provide a suitable $\mathrm{pH}$ condition for the next planting. Experiments were conducted in an open area to enable the treatment to blend with the natural environment similar to the actual practice. The corn residue which comprised corn stems and leaves were ground and mixed with soil in different concentrations $(0,20,60,80$ and $100 \mathrm{~g} \mathrm{~kg}-1)$. The moisture content and $\mathrm{pH}$ readings were measured for 60 days at 10 day intervals. Results showed that $20 \mathrm{~g} \mathrm{~kg}-1$ was the most suitable concentration for a soil conditioner as it can constantly increase its $\mathrm{pH}$ value of $\mathrm{R} 2=0.9457$ and $\mathrm{F}$ value of 234.36 and maintain soil moisture content, $\mathrm{R} 2=0.4217$ and $\mathrm{F}$ value of 164.82 .
\end{abstract}

